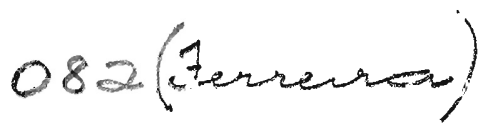

\title{
A outorga do prêmio "Teixeira de Freitas" ao professor Waldemar Ferreira.
}

Reunido em sessão solene, aos 29 de novembro de 1956, no Rio de Janeiro, sob a presidência do Dr. Trajano de MIranda Valverde, e em cumprimento de deliberação de seu Conselho Superior, o Instituto dos Advogados Brasileiros outorgou ao Professor Waldemar Ferreira o "Prêmio Teixeira de Freitas".

o "Prêmio Teixeira de Freitas" é a maior distinção que o Instituto dos Advogados Brasileiros confere anualmente aos juristas que maiores serviços tenham prestado à cultura juridica do País.

Dentre os juristas que foram homenageados com essa distinção citam-se Clóvis Bevilaqua, Carvalho de Mendonça e mais pròximamente Seabra Fagundes, Orozimbo Nonato e A. de Sampaio Doria. O prêmio consiste numa medalha com a efigie de Augusto Teixeira de Freitas, o consolidador da legislação civil no País, e de um diploma em pergaminho.

O professor Waldemar Ferreira foi saudado pelo sr. Отто GIL, da diretoria do Instituto, que salientou os grandes serviços por êle prestados ás nossas letras jurídicas. Professor de Direito Comercial da Faculdade de Direito de São Paulo, escreveu inúmeras obras de direito e ainda hoje exerce a advocacia. Em seguida, o professor Waldemar Ferreira usou da palavra, agradecendo a homenagem que lhe foi prestada, proferindo a seguinte oração: 


\section{Oração do Professor Waldemar Ferreira.}

"Confrange-se, nesta solenidade com que vós, meus eminentes confrades do Instituto dos Advogados Brasileiros, me enalteceis, fibra das mais sensíveis de minha emotividade espiritual, uníssona com a que gera a gratidão, e nem sempre a palavra exprime com eloqüência.

Jurista por vocação, mas principalmente por dever de ofício, eu me entreguei anos a fio ao cultivo das letras jurídicas, temente de mim mesmo, por convicto de que o feito, por mais bem feito, se mostra em regra imperfeito, e reclama o melhor. No fazimento do apenas iniciado, como no refazimento do já concluído, em perene revisão de meus conhecimentos, nunca me seduziu prêmio outro que não o de ordem íntima, decorrente da satisfação do dever cumprido. E êsse me bastou. Em momento algum, ainda que em entressonho esvoaçante, dêsses que nos povoam o cérebro em instantes de consciência meio dormida e meio acordada, se me apresentou a perspectiva de alcançada da glória, esquiva e longínqua, que ás vêzes se entrega aos que muito a disputam, mesmo porque a dos juristas não é dêste mundo.

Diante da honraria, com que estou sendo mimado, ponho o coração á larga; e como êle é, a um tempo, o princípio da vida e o da virtude, entro a sentí-lo em seus movimentos funcionais, já um tanto moroso é certo, mas ainda vivaz, regado de sangue que o tempo não tresmahou $\mathrm{e}$ generosamente me vem prolongando a existência. Consulto-o, em surdina; e êle me revela que, a despeito do muito que produzi, como abelha pródiga, não fiz tanto que pudesse justificar a mercê com que me aquinhoais.

Dissestes-me o contrário, meus insignes colegas, na formosa oração que acaba de ser proferida com alta benemerência por Отто GIL, a quem me prendem velhos laços de afeição.

Graças the rendo por ela. 
Tem esta homenagem para mim, e eu não o dissimulo, mais alto significado - o de ser dadiva de vossa clemência. Esta, nem sei mais em que antigo livro o li, é virtude de muito quilate, a que outras virtudes gloriosamente cedem: a caridade para fugir á vingança, a fortaleza para vencer a paixão e a liberalidade para engrandecer a humildade.

Não se nutre a clemência, por isso mesmo, só de bondade, como poderia parecer, posto se equilibre entre o muito rigor e a nímia indulgência. Nem se pode dizer que seja apenas forma de moderação. Antes será abrandamento no juízo, peculiar a quantos se dedicam aos misteres da justiça humana, nada mais que humana, por ser o homem, e o homem sòmente, o sujeito e o beneficiário do direito, que sem êle é vazio de sentido e seria palavra vã.

É a clemência a grã virtude dos homens da lei. Incompreende-se o advogado destituído dela, como o magistrado. Tendo de discernir, nos embates dos interêsses que se chocam nos cancelos dos tribunais, a fim de separar os legitimos dos que apenas ostentam a aparência de legitimidade, hâo da revestir-se de serenidade de ânimo, para que o sentimento não ceda à reflexão. Ésse é o instante exato em que opera a clemência. Toma um pouco à caridade para evitar os malefícios da vingança, que irracionaliza o homem. Requer outro tanto à fortaleza de espírito a fim de dominar a paixão, que oblitera os sentimentos, e deter a ânsia de revide, em que reside a fonte amarga das decepções.

0 debate judiciário, em que os litigantes deveriam brandir suas armas com punhos rendados, caracterizando-se por colóquio amável nos conceitos, posto expresso com firmeza e segurança nos golpes recomendados pela mais apurada arte da dialética, se reveste, na generalidade dos casos, do fragor de combates árduos e até de rudeza. A relação processual se estremece no anteparo de passadas 
mais violentas; mas não se rompe e a luta e lide chegam a termo, sem que os combatentes, depondo as armas, se mostrem desfigurados pelo ódio, dominados pela virtude da clemência, tôda feita de liberalidade.

Essa liberalidade advém do nobre senso de companheirismo propicio aos homens da lei, afeitos ao debate público, em que se extremam, divisando, em todos os lances, na pessoa do adversário, como que por via reflexa, a sua própria dignidade, e sentindo-a tão profundamente; cada qual em si mesmo, como na sua própria personalidade.

Não os separa êsse sentimento de respeito recíproco, que antes os irmana, de molde a poderem medir, no transe final e decisivo, o mérito do contendor, sem se desmerecer nesse reconhecimento, por haverem dado ambos à peleja tudo quanto suas fôrças opostas poderiam produzir, na defesa dos interêsses em presença, que cada um patrocinou com altaneria e bravura.

Não fôsse êsse o ambiente em que respiram os homens da lei e eu não poderia compreender, nem justificar, diante de mim mesmo, esta manifestação de clemente fidalguia, que assaz me surpreendeu quando a notícia dela me chegou, no meu recanto provinciano. Levei-a logo à conta da antiga e fraternal amizade com que tenho sido brindado por Levi Carneiro, homem da lei e homem de lei, em tôda a amplitude dos dois conceitos, que tem servido nosso País, dentro e fora de suas lindes territoriais, com as luzes de sua sabedoria e a magnitude de seu coração.

Desde que todavia a iniciativa, que dêle partiu, se homologou pela unanimidade dos componentes do Conselho Superior do Instituto dos Advogados Brasileiros, deliberando que se me atribuisse a medalha TeixeIra dE FreITAS, só então percebi que, muito mais que a benesse da amizade, no ato entrara a virtude da clemência, que ora sôbre mim recai. 
Bendigo dela; e mui desvanecido a agradeço, vendo, na pequena peça de bronze, que assinala o perfil de Teixeira dE Freitas, a exaltação do gênio, poderoso e fecundo, que se obnubilou na cena derradeira do drama espiritual em que a vida se lhe esvaiu. Quanto mais o examino, na sua vida e na sua obra, mais eu sinto que esta é quase desconhecida, em razão de sua extrema raridade, que a reconverteu, se assim me posso exprimir, ao estado de obra inédita.

O meu contacto com Teixeira de Freitas é de tôdas as manhãs. Não cause mossa o asserto. Vai para mais de trinta anos, deparou-se em mostruário de casa de quadros e molduras, nesta mui leal e heróica cidade de S. Sebastião do Rio de Janeiro, nas proximidades do largo do Rossio, pequeno e bem lançado busto em bronze, que me pareceu o do grande jurisconsulto. Detive-me. Tomei-o nas mãos. 0 tacto é comêço de posse. Examinei-o. Tinha diante de mim achado precioso. A chancela de Rodolfo Bernardelli, aposta no dorso do pequenino busto, me assegurou que se tratava de autêntica reprodução, em miniatura, do que se ostenta no momento que êste Egrégio Instituto dos Advogados Brasileiros em 1905 fêz plantar nesta cidade maravilhosa, na praça que então tomou o nome de Teixeira de Freitas.

Adquirida aquela admirável miniatura, desde então ela repousa sôbre minha mesa de trabalho, como se fôra a de nume tutelar, a inspirar-me em minhas cogitações de jurista.

Contemplo-a demoradamente nos instantes em que o espírito entra em devaneio aéreo, em suspensão no espaço, sem se fixar em nada, em busca de qualquer coisa indefinda, que se procura sem saber onde e que colabora todavia para a formação de nossas concepções intelectuais. Procuro, cruzado o meu com aquêle olhar de estátua, naquela fisionomia serena de sábio e de gênio, pela mão do artista paralisada na massa e que ao depois se fixou no 
bronze, penetrar no âmago do drama espiritual em cujo ato final Texeira de Freitas perdeu o último alento de vida; e aquêle olhar se mantém na expressão impassível de quem não tem nada mais que dizer á posteridade.

Manifestação primeira da pujança da personalidade de Teixeira de Freitas, ainda em formação, se tem no incidente que, estudante no Curso Jurídico de São Paulo, o impeliu, sem êxito, a argüir, perante o Govêrno Imperial, a suspeição do lente Conselheiro Clemente Falcão de Souza para o examinar no "ato" de direito comercial; e que o levou ao bacharelado no Curso Jurídico de Olinda. Tinha êle já então consciência, se não do que valia, ao menos do que prometia. Foi em 1835.

Menos expressivo não se mostrou o outro incidente que o levou a renunciar, em circunstâncias que abalaram o mundo jurídico nacional, em 1857, à presidência dêste Colendo Instituto dos Advogados.

Tendo ciência e consciência de que, elaborando a Consolidação das Leis Civis, por incumbência do Govêrno Imperial, o seu trabalho excedera, de muito, a simples coletânea de dispositivos legais e regulamentares em vigor no momento, compendiados em títulos, capítulos e parágrafos, devidamente articulados por colecionador paciente e cuidadoso, mas se revestira de originalidade, sem prejuízo da fidelidade às leis e regulamentos, que então vigiam — êle teve a sensação de que sua obra não tivera a virtude de receber a consagração devida. Externando seu ressentimento, escreveu êle, e isso em 1859, que "a sua única censura foi a mudez do silêncio quebrado apenas pelas vozes perdidas de dois artiguitos que inseriu o Diário do Rio de Janeiro, onde se nos falou de uns direitos mistos que até hoje não conhecemos e se nos disse que as leis deviam ser escritas em estilo bíblico".

Nesse mesmo ano todavia se viu Teixeira de Freitas, por sugestão de Nabuco de Araujo, contratado pelo Govêrno Imperial para elaborar o projeto do Código Civil. 
Na Consolidação, melhor é dizê-lo com palavras de Joaquim Nabuco, "o seu gênio tinha tido que se sofrear, que se curvar à lei escrita, à rotina dos tribunais, à estreiteza da velha jurisprudência, às vêzes obsoleta; fôra apenas chamado a repetir, não a reformar, a lei existente, e renová-la com maior clareza e individuação, qualquer que fôsse o seu defeito intrínseco, a sua incongruência e insuficiência perante a nossa época; no Código Civil podia, porém, exercitar as suas faculdades criadoras, dar a sua medida; não tinha mais que se escravizar às idéias e às formas do passado; tinha a mais ampla liberdade, podia adaptar a sua concepção do Direito, como a sua imaginação lhe inspirasse, às condições reais do nosso País, tal fôsse o seu gênio".

Entregando-se a êsse trabalho, que foi sendo publicado em volumes que se sucederam de 1860 a 1865; entregando-se ao estudo ininterrupto dos códigos e comentadores estrangeiros; padecendo contrariedades contínuas, estava Texxerra DE Freitas a terminar o Esbôço, que assim chamara seu projeto, quando se convenceú que a obra feita devia ser abandonada e substituída por outra, unificando-se a matéria civil com a comercial num único código de direito privado.

É de imaginar o esfôrço que êle fêz sôbre si mesmo para dominar-se; e não conseguiu. Repudiando sua própria obra, por considerá-la incondizente com o que a ciência jurídica lhe ditara à consciência, era preciso ter grande fibra e tomar a única atitude para pôr-se em conformidade com esta.

Nessa emergência, em 20 de setembro de 1867, êle se dirigiu ao ministro e secretário de Estado dos Negócios da Justiça, expondo as novas diretrizes que se deveria seguir. Bem se vê, disse na representação, que nisso punha "um nobre sentimento, um amor de perfeição que só a consciência pode recompensar. Se me negam a possibilidade moral de arranjar códigos de rotina, que só servem para atrair recompensas exteriores, então sou réu confesso". 
Sem embargo do acolhimento da nova proposta pela Secção de Justiça do Conselho de Estado, o Govêrno Imperial, em 18 de novembro de 1872, a recusou, dizendo o ministro da Justiça a TerxeIra de Freitas que assim procedia, "porque v. sa. declarou, na sua mencionada representação, que, pela desarmonia profunda entre o seu pensamento e as vistas do Govêrno Imperial, julga-se inabilitado para redigir aquêle projeto".

Notai bem nesta frase final. Nela disse o ministro da Justiça que TexxeIRA DE FreItas se julgava "inabilitado" para redigir o projeto de Código Civil. Nesse transe, faltou ao Govêrno Imperial exatamente a virtude da clemência, a alta virtude, que eu já disse ser dos juristas e é, também, a grande virtude dos reis e dos príncipes.

Nada terá mais ferido a personalidade de TeixeIRA DE Freitas de que aquela inclemência. Grande homem, no conceito hegeliano, sua superioridade levou-o ao conhecimento da verdade ou seja da vontade absoluta; e a exprimiu. Grande homem, embebeu-se da idéia, que o dominou, e de que se tornou o símbolo. $O$ sinal autêntico do direito dos gênios é o sucesso, que se reconhece ao poder, à gloria, à vitória.

Infelizmente, e que JoAQurm Nabuco ainda uma vez o diga, a razão de Terxeira de Freitas devia naufragar na emprêsa maior que projetava; à imensa sobrecarga do cérebro pela prolongação irremitente do esfôrço, da absorção intelectual, juntaram-se os desgostos, as contrariedades materiais da emprêsa, os prejuízos de tôda ordem, o desalento por causa da indiferença, aliás natural, de nosso País, tão pobre de ciência e fôrça especulativa, diante de feitos como o seu, em esfera a que raros podem remontar.

Por êsse mesmo tempo também lhe desferiu golpe de clava, que tão fundamente o feriu, o Conselheiro LafayetTe Rodrigues Pereira, dizendo, na introdução de seus Direitos de Família, que não preenchia também os intuitos da ciência a classificação fundada na diferença de direitos — "reais 
$e$ pessoais" que a comissão, que ministrou parecer sôbre a Consolidação das Leis Civis, tinha havido como "belo epílogo do direito civil, histórica e profunda quanto ao pretérito, rica de idéias e de elementos quanto ao futuro ou de constituendo, brilha e domina nela um pensamento capital, e vem a ser a diferença dos direitos reais e pessoais; diferença que, na frase bem cabida de que o autor se serve, é a chave de tôdas as relações civis". Em nota á terceira edição da Consolidação das Leis Civis, em 1875, TeIxeIra dE Freitas declarou que, para não alongar as notas dessa edição, "sofria desde já o pesar de não responder ponto por ponto", com defesa completa.

Mas esta, quem, em verdade a deu, foi Dalmacio Velez SARSFIELD, acolhendo aquela classificação no projeto, que então já havia elaborado para a Argentina, de Código Civil, em que não pouco do material reunido no Esboço, de Teixeira de Freitas foi aproveitado e, em boa parte, traduzido quase literalmente.

Com a morte de Teixeira de Freitas, em fins de 1883, seu nome se aureolou de glória, mas sua obra, a pouco e pouco se foi sumindo e convertendo-se de extrema raridade.

Não há muito, em tese de concurso para a livre docência de direito civil na Faculdade de Direito da Universidade de São Paulo, notei que o candidato, apoiando-se, em certo ponto, em texto de Esboço de Teixeira de Freitas, citou-o em castelhano. Manifestei-lhe, em conversa intima, minha estranheza, que teve revide imediato:

- Que havia eu de fazer? Tem sido em vão meu esfôrço para obter os volumes do Esboço. Não vi outro meio de o conhecer senão através de uma das edições argentinas, que é a com que trato, em falta da brasileira. Se não verti para o português o texto, que invoquei, foi pelo receio de infidelidade na versão...

Reeditou-se, há dois anos, o Esboço, enriquecido com opulenta introdução de Levr Carneiro. É já alguma coisa; mas ainda não é o bastante. Insta tirar do olvido, a que 
está condenada, tôda a obra de Teixeira de Freitas em edição monumental, para que a nova geração tenha a sensação do peso e medida de seu gênio.

Não dissimulo meu grande prazer íntimo quando recebo livros de juristas argentinos, nos quais os ensinamentos de Teixeira de Freitas se apresentam examinados, em seus vários aspectos, para bom entendimento dos textos do código civil argentino. Que riqueza de conhecimentos revelam êsses juristas exímios! Que entusiasmo vibrante os anima nas citações que daquele grão civilista fazem!

Permita-se-me, muito à puridade, pequenina confidência. Jamais se aninhou em meu espírito a mais mínima parcela de ciume, que os dicionaristas definem como zêlo de amor. Sou incapaz dêsse sentimento mercê, de um lado, da liberalidade que me domina em todos os transes de minha vida; e de outro, pela capacidade, que me é inata, de admirar o mérito dos outros, e mesmo de exalçá-los, sem a qual eu não teria levado a bom pôrto minha carreira de professor universitário, há pouco encerrada. Quando, todavia, leio os gabos com que os juristas argentinos se referem a Freitas (como do outro lado do Prata o chamam), eu como que me sinto tomado de uma pontinha de ciume nacional, no pressuposto de que êles, por direito de conquista, naturalizaram FreITas jurisconsulto argentino!

Nem seria demasia que algum jurista como tal o houvesse, em face da citação diária de Freitas nos compêndios e nas monografias jurídicas, editadas na majestosa capital portenha.

Circula como moeda corrente, no mundo jurídico argentino, uma das maịs belas edições do Esboco, em dois alentados tomos editados por A. Garcia Santos \& J. Roldan, de Buenos Aires, em 1909. Em seu frontispício apenas se tem isto: Código Civil, Obra fundamental del Código Civil, Argentino. Traducción castellana. No alto da página, apenas êste nome do autor: A. T. DE Freitas. Sem prólogo, sem explicação alguma que individualize o autor ou a ori- 
gem da obra, ao final do segundo tômo, após o contexto do art. 4.908, entre parentese, depara-se esta nota: (Aqui termina el Código Civil por el Dr. Antonio Teixeira de Freitas), quando êle é Augusto.

Êsse Freitas, quem será? Naturalmente, um jurisconsulto argentino, dirá de si para si mesmo o leitor desprevenido.

Pois, ora gracias que assim seja!

Êsse foi a grande prêmio de verdade concedido pela cultura jurídica da América à memória de TeIXeirạ DE Freitas. Não ficou êle quites com a posteridade com o monumento que se lhe erigiu no Rio de Janeiro; pelo contrário está, a despeito de tudo, vivo e revivo neste instante, nesta medalha de bronze, com que sou galardoado, mas muito mais, todos os dias, pelas referências e pelos debates dos juristas argentinos.

Estava a preparar esta oração, quando tive de interrompê-la, mercê de minha curiosidade inata, assim que me chegou, à mesa de meus trabalhos, o último fascículo, de abril-junho dêste ano, do Boletín de la Faculdad de Derecho y C. Sociales da Universidade Nacional de Córdova. De punhal em riste sôbre a brochura avanço a cortar as páginas dos cadernos de papel apenas dobrados. No prosseguimento dêsse trabalho, seguido por olhada de página em página, como se lesse num só golpe de vista, detenho-me na pág. 529, diante de um artigo do professor José A. BuTELER intitulado - Método del Código Civil, que se inicia com estas palavras de introdução:

"Entendo que não é ocioso, antes reputado de utilidade manifesta, que volvamos os cultores do direito civil a FrEITAS; e, sobretudo, que nossa preocupação vigilante seja a de predicar e encarecer a considerável influência que teve o pensamento do exímio jurisconsulto brasileiro na obra da codificação do direito civil argentino. Abrigo o pressentimento de que não haja, em nosso ambiente civilista atual, perfeita consciência dos extraordinários quilates da personalidade de Freitas como jurisconsulto e da grande impor- 
tância de seus trabalhos jurídicos. Eis por que escolhi o tema relativo ao método do Código Civil. É ali, precisamente, onde o pensamento de Freitas se mostra patente e decididamente inspirador da concepção sistemática elaborada pelo autor do Código Civil".

Prosseguiria, de bom grado, na leitura, desenvolvida como está a monografia em linguagem vivacíssima em tôrno do pensamento fundamental de TeIxeira dE Freitas sôbre metodologia e principalmente sôbre o princípio classificador dos direitos - pessoais e reais. Referirei todavia um ponto. Como se sabe, censurado por Alberdi de ter-se servido dos trabalhos do jurisconsulto brasileiro, Velez Sarsfield, lhe respondeu em palavras tais: "Perdóneme que yo, después de un detenido estudio de los trabajos del señor Freitas, los estime solo comparables con los del señor Savigny"

Explicando o sentido dêsse paralelo entre Freitas e SAviGNY, o insigne professor cordovês, na sua excelente monografia, revela a existência de documento inédito, no arquivo do Institudo de Direito Civil, em que se desvenda ter havido entre Freitas e Savigny nada menos do que se estendeu ao código civil argentino por influência direta de Freitas sôbre a obra de Vélez Sarsfield.

Denuncia isso o empenho na demonstração da tese de que se Teixeira de Freitas se comparou a Savigny, o paralelismo dos dois se deu naturalmente, sem que o jurisconsulto brasileiro tivesse a êste tomado seu pensamento, por isso mesmo original e fecundo. E sobreleva a tudo o reconhecimento da importância da obra e da personalidade de TeIxeIra de Freitas, que o escritor pressentiu em declínio e deu o brado de alarma.

Ouçâmo-lo nós, meus eminentes compatrícios do Instituto dos Advogados Brasileiros, confraternizados com os juristas argentinos para que se exalte o culto da personalidade e da obra de Teixeira de Freitas!". 